MATEC Web of Conferences 53, 01010 (2016)

DOI: $10.1051 /$ matecconf/20165301010

(C) Owned by the authors, published by EDP Sciences, 2016

\title{
Moisture Transfer in Ventilated Facade Structures
}

\author{
Vyacheslav Olshevskyi ${ }^{1}$, Elena Statsenko ${ }^{1, a}$, Tatiana Musorina $^{1}$, Darya Nemova ${ }^{1}$ and Anastasia \\ Ostrovaia $^{1}$
}

${ }^{1}$ St. Petersburg State Polytechnical University, Politekhnicheskaya, 29, Saint-Petersburg, 195251, Russia

\begin{abstract}
This article discusses the phenomenon of moisture transfer in the designs of ventilated facades (VF). The main ways of moisture transfer are defined. The negative factors connected with moisture accumulation and excessive moistening of insulation are given. The physical processes occurring in the gap of the building envelope due to saturation of air with water vapor are described. The dependence of the intensity of the mass transfer on the air velocity in the layer is considered. Much attention is paid to the selection of the optimum design of the facade, namely a system with or without grooved lines. The dependence of velocity and temperature on the width of the ventilated gap is established empirically for the constructions with open and closed grooves. Expediency of a design without grooves to effectively remove moisture is determined.
\end{abstract}

\section{Introduction}

High heat-shielding properties are considered to be one of the main reasons for the use of ventilated facades (VF) in modern construction. Proper identification of sources of moisture and moisture transfer mechanisms in protecting structures building envelope can significantly improve the designs of buildings and air conditioning system. After all, one of the conditions for increasing the durability of buildings and improving the indoor climate is to control the level of humidity $[1,2,3]$.

The problem of moisture transfer is extremely important. Moisture transfer represents the process of free and physically bound water movement due to gravity force and sorption, both molecular and capillary [4].

Thus, a quantitative calculation of moisture transfer is of great importance in the design of a multilayer building envelope, this exactly proves the relevance of this article. This article examines the impact of the design of ventilated facades on the air velocity in the gap, which the moisture transfer is directly dependent on $[5,6]$.

\section{Literature survey}

Moisture transfer in ventilated facade structures is covered extensively in papers.

In the article [1] conditions under which cold air can be filtered into an air gap are considered. In the publication [4] the optimum width of an air gap is found. In [7] the author considers the main problems of ventilated facades. In [8] analysis and assessment of the phenomenon of mass transfer in

\footnotetext{
${ }^{\text {a }}$ Corresponding author : staclena@mail.ru
} 
porous and disperse materials is carried out. In [11] the authors analyze the sufficient conditions of existence of free convective flow in a vertical parallel-plate duct. The authors of the publication [22] analyze the questions of natural ventilation, heat transfer and protection from overheating of ventilated facades. In the paper [27] the application of these designs in regions with a frigid climate is considered. In [28] the author investigates the methods for assessing thermal insulation of a wall with a ventilated facade, taking into account longitudinal air filtration.

\section{Setting goals and objectives}

As a result of the analysis the following research objectives were formulated:

- Identification of the optimum design parameters

- Numerical simulation of processes occurring in ventilated facades

- Clarification of the grooved lines influence on air exchange and moisture transfer in VF gap

\section{Materials and Methods}

The prerequisite for determining expediency of application of the ventilated facade is favorable moisture conditions. This circumstance defines design features of a façade [9, 10]. By intensity increase the main processes of moisture transfer are divided into:

- Water vapor diffusion (and surface diffusion in some porous materials)

- Convective transfer of water vapor with an air flow

- Gravitational and capillary water transfer through porous materials, leakages under hydrostatic pressure of water through openings such as cracks and macropores.

Convective transfer of water vapor is one of the main ways how it gets inside a construction gap together with air. In the same way rain water can get inside the facade structure through grooved lines. To prevent or reduce these effects the building envelope should have low air permeability.

Despite this, one of the key features of calculating the humidity conditions of facade systems with air gap is their increased air permeability. One of the main barriers to air filtration is facing, which should be denser than other layers of structure as it withstands climatic and anthropogenic impact [12$15]$.

Dense facing is one of the main parts of the ventilated facade structure, but since it is separated from the wall by the air gap, no obstacles for air movement will arise. Significant impact on the humidity conditions has transverse (extending perpendicular to the plane of the wall) air filtration. As external facing does not present an obstacle for the air movement and the internal design is often carried out without taking into account possible filtration, in some buildings the filtration has considerable impact on moisture conditions [16].

It is known that the ever-existing difference in temperatures inside and outside the building causes difference in partial pressure and, as a result, water vapor diffusion through the building envelope [17]. In the course of diffusion there is movement of water vapor from a region of high concentration to a region of low concentration. Diffusive transfer is characteristic of air, including air in pores of materials. Therefore, water vapor doesn't diffuse through nonporous materials such as steel, glass, some plastics, etc $[18,19]$

The calculation results and studies of heat and moisture transfer in the building envelopes prove that the zone of the greatest humidification is the layer of mineral wool insulation adjacent to the gap. Hence, it follows that the key factor is saturation rate of water vapor in the humid zone, not insulation thickness average humidity [20,21].

If the temperature drops to the dew point (the saturation temperature of water vapor), the condensation of water vapor occurs.

Lack of an air gap or its insufficient width under some conditions can cause moisture accumulation and insulation overwetting. Humidification of the insulant leads to:

- swelling and formation of microcracks in internal layers, 
- degradation of heat-insulating properties

- destruction of a porous body of insulation due to frost heaving

- adverse effect on its coefficient of heat conductivity

- corrosion of metal fastenings

- during the winter period due to a high temperature difference the humidity of insulant reaches its maximum. Because of this formation of an ice layer on mineral wool, a windproof membrane and on facing elements of a facade is possible.

It is therefore necessary to determine the conditions under which the insulation gap in the facade will remain unsaturated with moisture.

Removal of moisture from a humid zone may occur by diffusion of water vapor through the cover surface of the mineral wool insulation, the windproof membrane, the air gap and the facade facing layer. In addition, water vapor can be passed by an air flow through the air gap to the environment. Removal of moisture in the first case is small in comparison with the second one. Therefore it is necessary to provide possibility of removing all vapor from the zone of the greatest humidification by an air flow. Intensity of this technique depends on characteristics of an air gap (its width, height, etc.), which determine the air velocity in it.

Thus, for investigation of moisture transfer in the air space it is necessary to know the velocity and temperature of the air in the gap. It directly depends on the chosen design of the ventilated facade.

In designing ventilated facades much attention is paid to existence of grooved lines, which are a necessary operating condition of facades for diffusion removal of water vapor. The rustication grooves of the facing layer provide sufficient exchange with external air; therefore in most cases a vaporpermeable air compartment is optional.

However, due to the existence of these grooves it is impossible to prevent rain water and meltwater from getting on the back surface of the facing.

In addition, suction of cold outside air reduces the air velocity in the gap. This slows down the process of water removal. Drying rate of the moisture is influenced first and foremost by sufficient air motion and thermal radiation in the air gap.

Let us consider a stylized scheme of the ventilated gap between the "hot" plane $y=0$ (with Th temperature) and the cold plane $\mathrm{y}=\mathrm{h}$ (with Tc temperature). The height of the gap is equal to $\mathrm{L}$, and $\mathrm{L}$ $\gg h$. To determine the influence of air velocity on moisture transfer it is expedient to run the following experiment: humidified to saturation insulation is placed into the ventilated gap of the structure; velocity is measured at various width of the air gap, with grooved lines and without them, difference in mass of the saturated and dried insulant is determined at the highest velocity of FCF (free convective flow).

Producing a model of a facade, we consider the temperature difference between external and internal layers substantiated by work of heating systems. Both heating of a wall and heat transfer to the air gap are taken into account. It is supposed that external air comes into the air space through the bottom air holes. It rises in the air space and leaves through the top air holes. While the air rises, its temperature increases and its relative humidity changes. The humidity will change monotonously along the full height of the layer.

\section{Results and Discussion}

Intensity of a mass transfer is estimated by criterial dependence:

$$
N_{D}=\operatorname{const} \sqrt[4]{\sigma} \sqrt[4]{G r}=\operatorname{const} \sqrt[4]{\sigma} \sqrt{R e}
$$

where $N_{D}$ - the diffusion Nusselt number, $\sigma$ - the Prandtle number, $R e$ - the Reynolds number, const $=\mathrm{O}(1)$ - a constant; for FCF condition in a confined gap we accept const $\approx 0.5$.

Let us carry out the experiment and measure air velocity and temperature in the air gap depending 


\section{MATEC Web of Conferences}

on its width. The most widespread device for measurement of air velocity in technical systems is the hot-wire anemometer.

The results of measurements with open (bottom lime) and closed (top line) grooved lines respectively:

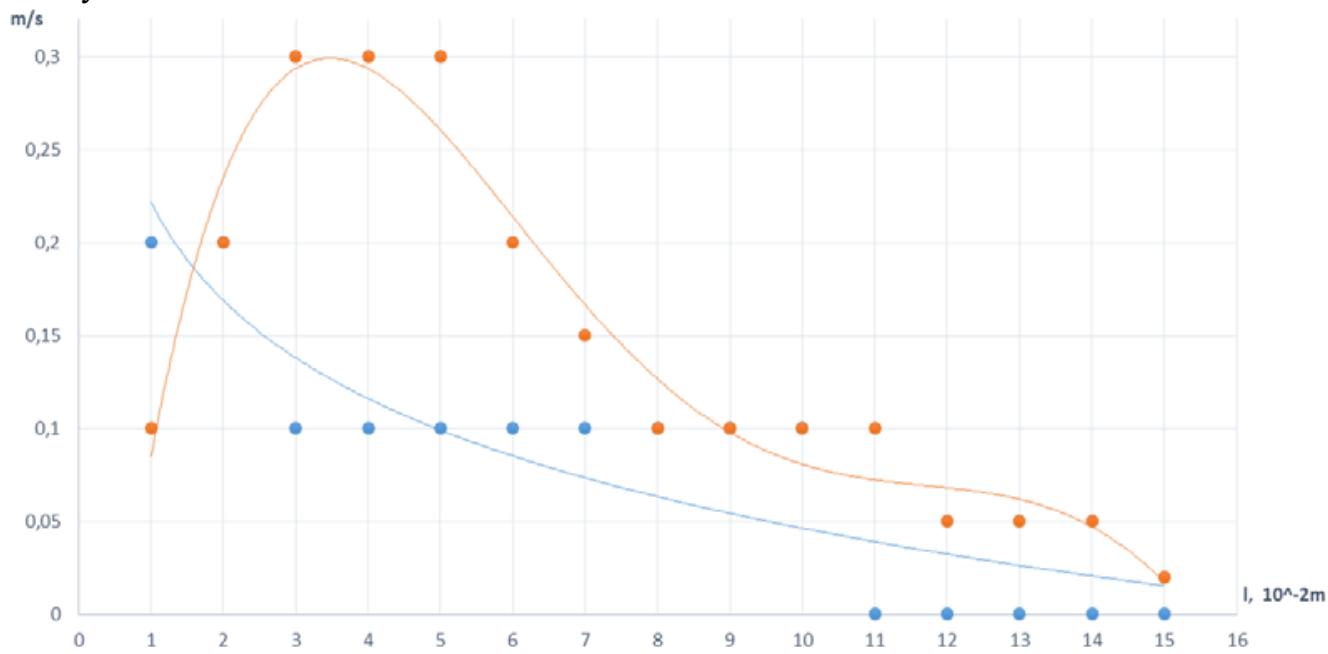

Figure 1. Air velocity as function from the geometrical sizes of the VF channel

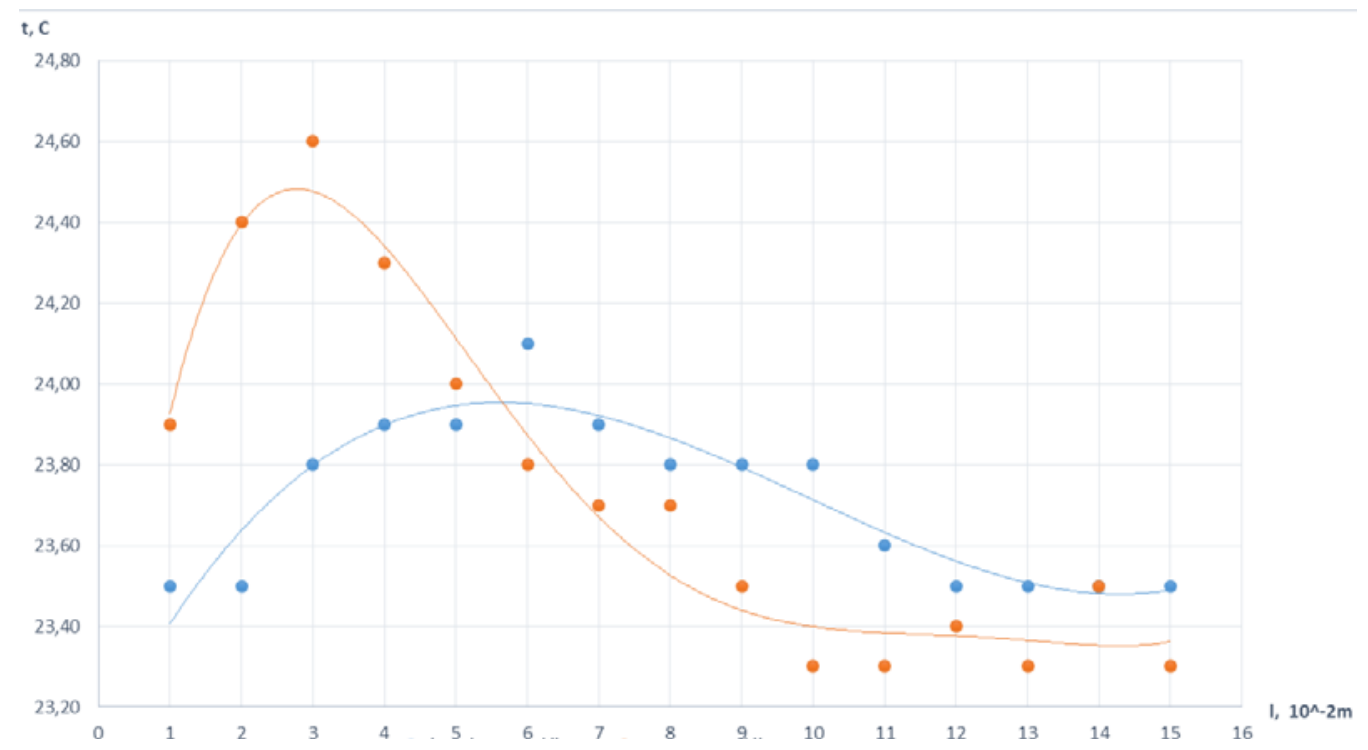

Figure 2. Air temperature in the gap as function from the geometrical sizes of the VF channel

On the basis of the data obtained experimentally it is possible to draw the following conclusions:

- maximum draught is observed in the "ideal" air gap

- grooved lines "overturn" FCF in a vertical gap

- the "ideal" layer is necessary for the normal work of insulation

- in a design with the closed grooved lines the insulation won't be saturated since the higher velocity and temperature values promote moisture removal.

\section{Conclusions}


Broad use of ventilated facade systems resulted in need of developing methods of forecasting moisture conditions of a building envelope.

Quantitative calculation of moisture transfer is one of the most important problems in designing the building envelope.

Rather high velocity values in the gaps of VF designs without grooved lines are one of the prerequisites for determining expediency of their application for effective moisture removal.

\section{References}

1. D.V. Nemova, V.Ja. Olshevskyi, D.N. Cejtin, Nauchno-tehnicheskie vedomosti SPBGPU, Jekonomicheskie nauki, 295-301 (2013)

2. S. Kosanović, A. Fikfak, Energy and Buildings, (2015)

3. I. Čerpes, N. Pandol, A. Fikfak, European Countryside, 6 (3), 225-242 (2014)

4. V.A. Emel'janova, D.V. Nemova, D.R. Miftahova, Inzhenerno-stroitel'nyj zhurnal, 6, 67-74 (2014)

5. A.F. Ostrovaja, M.R. Petrichenko, E.A. Stacenko, Applied Mechanics and Materials, 725-726 (2015)

6. M.R. Petrichenko, Second Edition St. Petersburg State Polytechnical University Journal. Physics and Mathematics, 143-149 (2012)

7. N. Vatin, , M. Petrichenko, D. Nemova, Applied Mechanics and Materials, 633-634, 1007-1012 (2014)

8. A. Fikfak, Journal of Architecture and Urbanism, 37 (4), 257-267 (2013)

9. N.I. Gamajunov, S.N. Gamajunov, Vestnik TvGTU, 128, 22, 46-54 (2010)

10. S.V. Kornienko, Inzhenerno-stroitel'nyj zhurnal, 2, 18-23, (2012)

11. S.V. Kornienko, Inzhenerno-stroitel'nyj zhurnal, 7, 43-49, (2012)

12. M.R. Petrichenko, M.V. Petrochenko, Nauchno-tehnicheskie vedomosti SPBGPU, 2, (2012)

13. D.V. Petrosova, Sankt-Peterburg, 118 (2012)

14. E.B. Yevtushenko, M.V. Petrochenko, Magazine of Civil Engineering, 8,38-45

15. V.G. Gagarin, Moskva, 396 (2000)

16. N. Lipovac, Prostor, 19 (1), 2-17 (2011)

17. A.S. Gorshkov, D.Ju. Popov, Magazine of Civil Engineering, 8, 5-9 (2010)

18. A.A. Emel'janov, Promyshlennoe i grazhdanskoe stroitel'stvo, 62-71 (2013)

19. D.A. Zhukov, Stroitel'stvo: nauka i obrazovanie, 2-15 (2012)

20. N. V. Shilkin, AVOK, 1, 12-20 (2005)

21. M.R. Petrichenko, D.V. Petrosova, M.V. Petrochenko, NTV SPbGPU. Fiziko-matematicheskie nauki, 68-72 (2012)

22. V.G. Gagarin, V.V.Kozlov, Stroitel'naja fizika v XXI veke, 73-80 (2006)

23. V. G. Gagarin, V. V. Kozlov, I. A. Mehnecov, AVOK, 8, 71-80 (2005)

24. M. R. Petrichenko, X. Rakova, M. Vyatkin, , T.A. Musorina, D. Kuznetsova, Applied Mechanics and Materials, 1101-1106 (2015)

25. J.Li, Y.Chow, D.H.C. , Centre for Sustainable Energy Technologies (CSET), 198-203 (2014)

26. Jun Hana, Lin Lua,Jinqing Penga, Hongxing Yanga, Energy and Buildings, 204-209 (2013)

27. V.N. Bukhartsev, M.R. Petrichenko, Power Technology and Engineering, 5, 374-377 (2011)

28. Alin V. Rosca, Ioan Pop, International Journal of Heat and Mass Transfer, 355-364 (2013) 